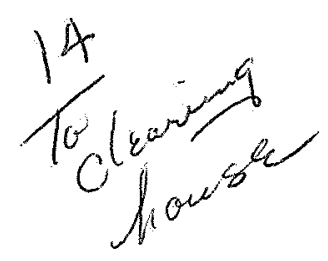

$N 71-12940$

NASA TECHNICAL

MEMORANDUM

NASA TM X-52927

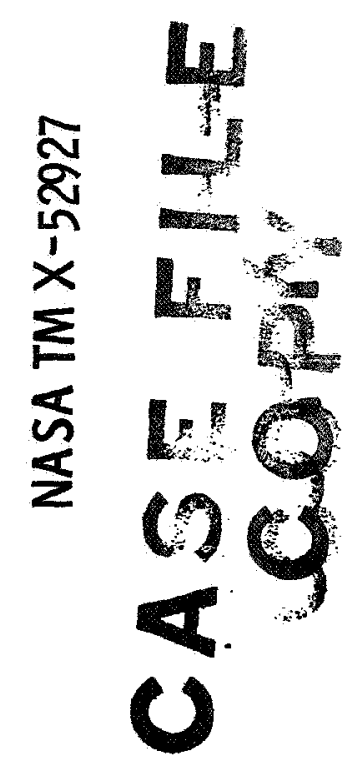

EFFECT OF FACILITY BACKSPUTTERED MATERIAL ON PERFORMANCE OF GLASS -COATED ACCELERATOR GRIDS FOR KAUFMAN THRUSTERS

by Robert T. Bechtel, Bruce A. Banks, and Thaine W. Reynolds Lewis Research Center

Cleveland, Ohio

TECHNICAL PAPER proposed for presentation at

Ninth Aerospace Sciences Meeting sponsored by the American Institute of Aeronautics and Astronautics

New York, New York, January 25-27, 1971 


\title{
EFFECT OF FACILITY BACKSPUTTERED MATERIAL ON PERFORMANCE OF GLASS-COATED ACCELERATOR GRIDS FOR KAUFMAN THRUSTERS
}

\author{
Robert T. Bechtel, Bruce A. Banks, and Thaine W. Reynolds \\ National Aeronautics and Space Administration \\ Lewis Research Center \\ Cleveland, Ohio
}

\begin{abstract}
Testing of glass coated accelerator grids on mercury bombardment thrusters has revealed the presence of conductive coatings of facility backsputtered material on downstream glass surfaces. Tests in two vacuum tanks of different sizes indicated that these backsputtered coatings improve the beam current extraction capability of the grid. Results from these tests lead to several limitations on the type of facility which can be used for testing glass coated grids. Tests of several grids with different geometries have shown that grids which do not depend on backsputtered material for high beam current ( $1.5 \mathrm{amp}$ ) capability can be fabricated.

\section{Introduction}

Electron bombardment thrusters which can operate efficiently at power input levels from 2 to 3 kilowatts and specific impulses of 2000 to 3000 seconds are currently of interest for some primary propulsion applications. $(1,2)$ Such thrusters are currently being studied. $(3,4)$ The $30-\mathrm{cm}$ diameter thrusters provide much better performance at low specific impulse when operated with glass coated accelerator grid rather than the conventional, two grid system. However, backsputtered material from the vacuum tank walls has been observed on the downstream glass surfaces which are exposed to the vacuum tank. A series of tests was run to determine any significant effect that these backsputtered coatings have on grid performance. The tests were run in vacuum tanks where the amount and type of electrically conductive material which could be sputtered could be controlled or eliminated. These coatings of backsputtered material significantly affect the beam current extraction capability of the glass coated grid.

The effect of vacuum tank size on the build up of conductive coatings and the effect of exposure to atmosphere on these coatings were investigated. Two grid geometries which simulated a conductive coating on the glass surfaces were also tested.

\section{Apparatus}

The thruster used in this investigation was a $30-\mathrm{cm}$ diameter electron bombardment thruster with a hollow cathode, described in Refs. 3 and 5. A sketch of the thruster is shown in Fig. 1. One of two similar glass coated accelerator grids were used for all but one test. The fabrication and performance of glass coated accelerator grids are detailed in Refs. 3, 5, 6, and 7. A cross-sectional sketch of the glass coated grid is also shown in Fig. 1. A plasma bridge neutralizer ${ }^{(8)}$ was used in all tests.
Tests were conducted in two vacuum tanks. The smaller tank was $1.5 \mathrm{~m}$ - diam. by $4.6 \mathrm{~m}$ long. A stainless steel target was located $2.3 \mathrm{~m}$ from the plane of the accelerator (fig. 2(a)). A liquid nitrogen cooled copper baffle was used to maintain pressures in the low $10^{-5}$ torr range during thruster operation. A photograph of this tank is shown in Fig. 2(a). For several tests, this tank was lined with an electrical insulating material made of $50 \%$ aluminum oxide and $50 \%$ silicon dioxide. Baffles of this material were used to eliminate nearly all lines of sight between the accelerator grid and all metal surfaces. In this way, the possibility of conductive material depositing on the accelerator grid was virtually eliminated. A photograph of the lined vacuum tank is shown in Fig. 2(b).

The larger vacuum tank was $7.6 \mathrm{~m}$-diam, by $21.3 \mathrm{~m}$ long. (9) This facility also had a liquid nitrogen cooled baffle which made pressures less than $5 \times 10^{-6}$ torr possible during thruster operation. This tank was always operated without insulating liners.

For most runs, clean glass slides were mounted in the vacuum tank in order to estimate the amount of backsputtered material. Some slides were mounted downstream facing the thruster to permit direct beam ion impingement. Most slides were mounted near the plane of the accelerator facing the vacuum tank to collect backsputtered materials. Some of these latter slides were left in position throughout the test while others were mounted on a rotating wheel which permitted one slide to be exposed for a segment of a run.

In order to determine the existence of any conductive coating on the downstream glass wall of the accelerator grid, a special probe was fabricated to fit into a grid hole. The resistance between the probe and the accelerator grid substrate material was measured using a digital ohm meter. A cross-section of the probe and grid is shown in Fig. 3. The accuracy of such a measurement depends on the amount of contact resistance encountered. Since this variable could not be easily controlled, these probe measurements can only be considered to provide qualitative measure of any coatings which might be present on the glass surface. For all tests where quantitative results are compared, the probe was used in the vertical direction only so that the amount of contact resistance was determined by the weight of the probe and would be consistent for all tests.

\section{Procedure}

\section{Thruster Operation}

The same thruster start-up procedure was used for 
all tests reported. The cathode tip, neutralizer tip, distributor heaters, and positive and negative extraction voltages, were turned on at the beginning of a preheat period of 30 to 70 minutes. After the preheat period, mercury propellant was fed to the neutralizer. Within 10 minutes, a discharge was established between the neutralizer and neutralizer anode. At this point, propellant was fed to the cathode and a discharge established between the cathode and cathode keeper. The discharge between cathode and thruster anode was initiated almost simultaneously and an initial ion beam was extracted. The initiation of the main discharge and extraction of the ion beam was used as the time reference for the start of the test. At this point, propellant was fed through the distributor directly into the discharge chamber (fig. 1).

Both cathode and main vaporizers, emission current, and extraction voltages were set to provide nominal propeliant flow rates required for $1.5 \mathrm{amp}$ beam current operation. ${ }^{(3)}$ Vaporizer temperature and heater powers were used as guide lines for the propellant flow rates since accurate propellant flow readings cannot be obtained until the system has reached thermal equilibrium. This requires approximately 1 hour ${ }^{(3)}$. Maintaining constant propellant flows was difficult during periods of rapidly changing beam current. Propellant flow rates, emission current, and extraction voltages were generally kept constant throughout a test.

\section{Grid Documentation and Cleaning}

The grid condition before and after tests was documented by inspection under a microscope and by photomicrographs of selected grid areas. Ten-power photographs were also taken of larger areas. The same area was documented before and after each test for comparison. Electrical resistance measurements were made of the glass surface as described in Fig. 3 before and after many tests.

The grid was cleaned before several of the tests in order to remove any conductive coating which might be present from previous tests. This was accomplished by washing the grid in aqua regia, followed by sodium hydroxide solution, and finally aqua regia plus sulfuric acid. After the acid wash the grid was rinsed with distilled water and acetone and dried in a nitrogen atmosphere. This procedure effectively removed all traces of conductive coatings on the glass surfaces (fig. 4(a)). Some erosion of the metal substrate was experienced. The erosion was most severe where the glass coating meets the downstream face of the molybedenum substrate (fig. 4). Most of this erosion occurred during the first acid cleaning.

\section{Results and Discussion}

\section{Effect of Initial Coating}

The first two tests were run in the $1.5 \mathrm{~m}$ diameter vacuum tank with the metal walls exposed (fig. 2(a)). The grid had been run for a period of approximately 90 hours prior to test 1 , during which time a coating of conductive material had built up on the downstream glass surface of the grid. The existence of a conductive coat- ing was inferred from several facts. Visual inspection prior to test 1 showed a coating existed on the glass surface. Resistance measurements after test 1 showed a conductive coating existed (fig. 5). The resistance values were generally less than 10 megohms. Only one of the 120 holes sampled had a resistance greater than the limit of the instrument $(17 \mathrm{M} \Omega$ ). The average values for the other holes was about 1.4 megohms.

The grid was acid cleaned between tests 1 and 2 . Measurements before test 2 indicated a resistance in excess of the instrument limit. Measurements after test 2 showed the presence of a conductive coating. In this case, 31 of the 120 holes sampled had resistance values in excess of the instrument limit. The average for the other holes was 4.9 megohms. This was despite the fact that the run times for both tests were almost the same. The lower resistance values after test 1 indicate that the coating observed at the start of test 1 was probably conductive.

Figure 5 shows the resistance of the coating to be many orders of magnitude lower near the periphery than in the center of the grid. This is attributed to two facts. First, a neutralizer shield screen (fig. 1) which was presented in tests 1 and 2 provide a metallic source of backsputtered material which intercepted beam ions Ieaving the thruster at high angles of divergence. It is therefore probable that this material would arrive at the grid periphery in greater quantities than at the grid center. Also, probe measurements have shown that the beam current density at the grid periphery is about an order of magnitude lower than the beam current density in the center. Thus, any cleaning of the glass surfaces due to ion bombardment of these surfaces would be greatly reduced.

The beam current-time plots for tests 1 and 2 are given in Fig. 6. Test 1, with the previously deposited coating, required 40 minutes to reach $1.5 \mathrm{~A}$ beam while test 2, after acid cleaning, required 110 minutes to reach the same beam current under the same start-up conditions. The longer time requi red is attributed to the fact the conductive coating, removed by the acid cleaning, had to be replenished in the extra 70 minutes.

\section{Effect of Back Sputtered Conductive Material}

To further investigate the effect of a conductive coating resulting from back-sputtered facility material, several tests were run in the $1.5 \mathrm{~m}$ diameter vacuum tank with insulating liners in place (fig. 7). Test 3 was run with a grid initially free of a conductive coating. During the 650 minutes of test, no source of backsputtered conductive material was available. Figure 7 shows the beam current to be near constant $0.5 \mathrm{amp}$ for the entire test indicating the need for a conductive coating to extract a $1.5 \mathrm{~A}$ beam for this type of grid.

Further evidence of the need for a conductive coating was found from tests 4 and 6 . The grid was cleaned before each test and resistance measurements showed no conductive coating. In both tests, the thruster was initially run in the $1.5 \mathrm{~m}$ diameter vacuum tank with the insulating liners (test segments $4 \mathrm{~A}$ and $6 \mathrm{~A}$ ). As shown 
in Fig. 7, the performance duplicated that of test 3. After 240 minutes of operation in test 4 , a $30 \mathrm{~cm}$ diameter copper target, was inserted in the beam approximately $75 \mathrm{~cm}$ downstream of the accelerator grid (test segment B). This target intercepted approximately $30 \%$ of the total beam current. An immediate increase in beam current was noted as the copper target material was sputtered back to the grid. The beam current leveled off at $1.25 \mathrm{~A}$ after 110 minutes of operation.

A similar procedure was followed in test 6 . The only difference was that the target was $45 \mathrm{~cm}$ in diameter and made of platinum. This target intercepted about $55 \%$ of the beam current. The larger target afforded a higher flux of target material arriving at the grid. The beam current increased more rapidly during test $6 \mathrm{~B}$ than in test $4 \mathrm{~B}$, requiring only 55 minutes to reach $1.5 \mathrm{~A}$ beam current.

Tests 3, 4, and 6 offer proof that the grid used could not extract a beam current much greater than $0.5 \mathrm{~A}$ without an additional coating of conductive material on the downstream glass surfaces and that the rate at which the beam current increased depended on the rate of deposition of the conductive material.

After several of the tests, a deposit of conductive material was noted on the discharge chamber (upstream) side of the glass. A typical deposit of this type is shown in Fig. 8(a). Figure 8(b) shows a similar grid which is free of this conductive coating. Both grids were capable of extracting a $1.5 \mathrm{~A}$ beam current after the downstream glass surfaces were sufficiently coated with conductive material. Thus, in the thruster investigated, a conductive coating on the discharge chamber (upstream) side of the grid was not required to extract a $1.5 \mathrm{~A}$ beam current.

\section{Facility Size}

The time required to reach a beam current of $1.5 \mathrm{~A}$ depends on the initial condition of the grid. If the grid has an initial conductive coating, then the beam rise time is determined by the thermal response of vaporizers and other thruster components. This time is typically less than 1 hour and depends on the startup procedure followed. If the grid does not have an initial conductive coating, then the beam rise time is determined by the arrival rate of back sputtered material at the accelerator grid. This arrival rate is a function of the facility or target design and location.

A calculation of the thickness of the coating on the thruster centerline in monolayers as a function of the number of beam ions in ampere-minutes is presented in Fig. 9. This calculation is based on the following assumptions:

1. The energy of the beam ions is $800 \mathrm{eV}$ (net accelerating potential)

2. The sputtering yields at $800 \mathrm{eV}$ are ${ }^{(10)}$

a. Platinum, 1.5 atoms/ion

b. Copper, 2.0 atoms/ion

c. Stainless steel, 0.9 atoms/ion
3. All sputtered material incident on the glass surfaces of the grid adhere to tho se surfaces.

4. The beam current density at a given location specified by an axial distance from the thruster, $Z$, and an angle, $\varphi$, from the axis is given by the relation $[J(Z, \varphi) / J(Z, 0)]=e^{-[\lambda(1-\cos \varphi)]^{n}}$. This equation gives good agreement with experimental probe results. Values of $\mathrm{n}=1,0$ and $\lambda=25$ were evaluated using experimental results of Ref. 4 .

The vacuum tank geometries providing the thickest coating in a given time are those using a target in the $1.5 \mathrm{~m}$ diameter insulated vacuum tank. Of these two, the platinum target ranks higher than the copper by virtue of its larger diameter. These two geometries are followed by the $1.5 \mathrm{~m}$ diameter vacuum tank without target or insulating liners and the $7.6 \mathrm{~m}$ diameter facility.

Another method of ranking facility geometries according to sputtered material arrival rate is the use of glass slides to collect sample materials. The thickness of the coating on the glass slides is assumed proportional to the thickness of the coating on the glass surfaces of the grid. The thickness of the coating on the slides is directly related to the reduction of the optical transmission of the glass slides. The reduction in the optical transmission of a slide for an entire run was determined by using a densitometer. The average reduction of optical transmission per unit time was computed from this value and the total run time.

The rate of reduction for all tests are given in Table I along with other pertinent test data. These include run times, ampere minutes, and the condition of any coating on the glass surfaces of the grid as determinted by resistance measurement or other means. Four tests which are of particular interest in determining the effect of facility size are tests $2,4 \mathrm{~B}, 6 \mathrm{~B}$, and 11. In each of these tests the grid was initially free of a conductive coating. The thruster was run as long as necessary to achieve a $1.5 \mathrm{~A}$ beam. This time ranged from 55 to 1500 minutes.

Four criteria were used to determine the effect of facility size and configuration and the results are shown in Table II. These were the calculated values of ampere-minutes required to reach a given thickness of sputtered material, the ampere-minutes and total minutes required to reach the maximum beam attained, and the rate of reduction of the optical transmission of the glass slides. This provides a ranking of facilities in agreement with the calculated curves of Fig. 9 and with the beam current-time profiles of tests $2,4 \mathrm{~B}, 6 \mathrm{~B}$, and 11 presented in Fig. 10.

\section{Deterioration of Conductive Coating}

Test 4 was carried beyond segments $A$ and $B$ as already discussed to determine the permanance of the sputtered coating after the source had been removed. The copper target was removed after test $4 \mathrm{~B}$ and the thruster continued to operate at $1.25 \mathrm{~A}$ beam without any change for 240 minutes throughout test $4 \mathrm{C}$ (fig. 9). The glass surface condition was believed to be conductive based on 
the beam current capability. Mea surements were not made at this point, however. After test $4 \mathrm{C}$, the vacuum tank was bled to atmosphere and repumped after $30 \mathrm{~min}$ utes. The surface condition at this point was not known. The thruster was restarted for test 5. Figure 11 shows that the beam current rose quickly, requiring only 50 minutes to reach a maximum value. However, the beam did not quite reach the $1.25 \mathrm{~A}$ level of test $4 \mathrm{C}$ and continued to decrease to $1.0 \mathrm{~A}$ at the end of the $400 \mathrm{~min}-$ ute test. The conductivity of the glass surface after the test but before exposure to atmosphere is not known. The grid was removed from vacuum and the surface conductivity measured after test 5 . The surface was not conductive. Based on this test, it was concluded that the conductive copper coating which had been deposited during test $\mathbf{4 B}$ was harmed, possibly by oxidation, when briefly exposed to atmosphere.

Test 6 was run using a platinum target, providing a source metal which would not oxidize when exposed to atmosphere. The time history of test $6 \mathrm{~A}$ and $\mathrm{B}$ closely paralleled that of test $4 \mathrm{~A}$ and $\mathrm{B}$. When this grid was removed from vacuum, it was found that the glass surface was highly conductive, with resistance measurements less than $100 \mathrm{ohms}$ for most measurements. Using the curve of Fig. 9 and the total ampere-minutes of test 6B, Table I, an approximate thickness of 550 monolayers of platinum could be expected. The same analysis applied to tho se cases involving conductive copper and/or iron coatings results in expected thicknesses of 300 monolayers or more (tests 1, 2, 4B). In addition, the conductivity of copper is about 7 times that of platinum. Yet the platinum coated grid had measured conductivities five orders of magnitude greater than a copper coated grid. A possible cause of this difference is a surface effect resulting from oxidation in tho se cases involving copper and/or iron coatings.

The grid was tested with the platinum coating in the $1.5 \mathrm{~m}$ diameter facility with insulating liners in place. The start-up procedure differed slightly in that the propellant flow was started about 10 minutes before the high voltages were applied to the extraction system. The beam current reached $1.5 \mathrm{~A}$ in 5 minutes from the time the extraction voltages were turned on. The test was continued for a total of 400 minutes with no noticeable change in beam current.

This grid was also tested in the $7.6 \mathrm{~m}$ diameter vacuum tank. Beam current rise times of 8,22 , and 35 minutes were observed in three separate tests. This is compared with test 12 (Table I) in which the beam current did not exceed $0.7 \mathrm{amp}$ in 705 minutes of testing. As shown previously (figs. 9 and 10 ), the flux rate of back sputtered material is so small that the thickness of any coating on glass surfaces is insignificant in the first 10 hours.

The results of tests 4 and 5 (fig. 11) indicate that exposure to atmo sphere of a copper or iron coating has an effect on that coating which results in decreased beam current capability. This is shown by several tests in . the $7.6 \mathrm{~m}$ diameter facility. Figure $12(\mathrm{a})$ shows the results for tests 13 through 16 . The grid was free of conductive material at the start of test 13. A total time of
833 minutes was required to build up the needed conductive coating to yield a $1.5 \mathrm{~A}$ beam. The test was terminated shortly thereafter but the grid was kept at a $10^{-7}$ torr vacuum for 8 hours. Test 14 was then started. In this case, a time of 75 minutes was all that was needed to achieve a $1.5 \mathrm{~A}$ beam. At the end of test 14 , the grid was exposed to atmosphere, and the resistance of the coating on the glass surface was measured and found to be non-conducting. Tests 15 and 16 were run in the same sequence as 13 and 14. Again the initial start required 940 minutes and the restart 60 minutes to reach a $1.5 \mathrm{~A}$ beam. When removed from vacuum, the coating on the glass surface was found to be non-conducting. The performance of the grid strongly suggests the presence of a conductive coating at the end of tests 13 and 15 and throughout tests 14 and 16 . This coating loses its conductivity when the grid is exposed to atmosphere. This was confirmed in a separate test in the $7.6 \mathrm{~m}$ diameter facility. A probe identical to that of Fig. 1 was installed inside the facility. This probe could be inserted into a grid hole to provide a glass surface resistance measurement while still in vacuum. Resistance measurements were made with an instrument having a $10^{5}$ megaohm capability. At the start of the test, the surface resistance was in excess of 20,000 M 2 . The resistance decreased to $300 \mathrm{M} \Omega$ at a beam current of $0.75 \mathrm{amp}$ and to less than $20 \mathrm{M} \Omega$ at a beam current of 1.5 amps. However, when the grid was exposed to atmosphere, the resistance increased to $300 \mathrm{M} \Omega$ within several minutes, and increased to several thousand megohms within several additional minutes.

Figure 12(b) shows the behavior of the accelerator drain current for each of these tests. For tests 13 and 15 the drain current remained below $10 \mathrm{~mA}$ until the coating on the glass was sufficient to extract a $1.5 \mathrm{~A}$ beam current. At this point there was a marked increase in the drain current. This occurred in every case where the grid required many hours to accumulate the required coatings. In tho se cases where the grid had an initial coating sufficient to extract a 1.5 A beam current, the rate of increase of drain current at the start of a test would vary. However, the drain current always showed signs of increasing to a value in excess of $20 \mathrm{~mA}$.

Exceptions occurred in test 2, where the test was terminated shortly after the beam current reached $1.5 \mathrm{~A}$, and the drain current remained less than $8 \mathrm{~mA}$. In tho se tests with the copper target (4A, B, C, and 5) the accelerator drain current did not increase above $8 \mathrm{~mA}$ and the beam current only reached $1.25 \mathrm{~A}$. In all tests where the conductive backsputtered material was absent or negligible, and the grid geometry was not altered to simulate a conductive coating, the accelerator drain current was always less than $8 \mathrm{~mA}$.

A coating sufficient to provide a 1.5 A beam current apparently causes high accelerator drain currents, This represents a power loss of several watts, but more important could affect grid lifetimes. However an investigation of this phenomenon is beyond the scope of this paper.

Table I shows the beam ampere minutes of each 
run and corresponding approximate number of monolayers of backsputtered material expected to be deposited on the grid, based on the calculations of Fig. 9 . Note that all grids with an initial conductive coating required less than 50 monolayers of backsputtered material, and all but one required less than 5 monolayers to reach a $1.5 \mathrm{~A}$ beam. All grids without an initial coating required more than 50 and as high as 440 monolayers of backsputtered material to reach a $1.5 \mathrm{~A}$ beam. In the case of test 12,42 monolayers on a grid with no initial coating were not sufficient to produce a $1.5 \mathrm{~A}$ beam.

No conductive coating was detected on the grid after any of tests 11 through 16 , yet a $1.5 \mathrm{amp}$ beam current was realized in each of these tests. However a conductive coating was detected after tests 1 and 2 . Figure 9 predicts a thicker coating for both tests 1 and 2 than for any of tests 11 through 16 . This suggests that some minimum coating thickness of vacuum tank material must be built up in order for the coating to withstand expo sure to atmo sphere.

The deterioration of the beam current capability in test 5 after exposure to atmosphere (fig. 11), and the fact that a grid coated with platinum is independent of atmospheric exposure (tests 7 through 10) lead to the conclusion that a copper and/or iron coating is susceptable to some process such as oxidation which, in the case of thin deposited coatings, destroys the conductance of the grid and hence its beam current capability. These facts also suggest that sputter deposition of a material which will not oxidize may be a possible final step in the fabrication of glass coated accelerator grids.

\section{Effect of Neutralizer Shield Screen}

Table I shows tests 11,13 , and 15 to be almo st identical in configuration and procedure but to vary by almost 700 minutes in the time required to reach a $1.5 \mathrm{~A}$ beam. The ampere-minutes differ by 470 or approximately $50 \%$. The reason is an additional source of backsputtered material presented by the neutralizer shield screen (fig. 1). The configurations tested are shown in Fig. 13. This includes both the neutralizer shield screen and the facility ground potential screen. In test 14 , both screens were positioned such that ions leaving the extraction grid at high angles of divergence would strike the metal surfaces. The position of these screens define a half angle, $\theta$, of a beam envelope. All beam ions inside this envelope will have to travel to the facility wall to sputter metal and the sputtered material will have a smaller solid angle which will permit it to return to the grid. The angle was increased slightly by retracting the neutralizer shield screen for test 13 as shown in Fig. 13. This increased the time required to reach a $1.5 \mathrm{~A}$ beam by about 190 minutes (fig. 14). Retracting the facility ground screen increased the beam current rise time by 560 minutes. The geometry of test 11 defined a beam envelope of approximately 85 degrees and virtually eliminated the effect of sputtered material from thruster components.

In all tests except $1,2,11$, and 13 the sputtered conductive material from these screens was reduced to a negligible amount by either covering them with insulating material or moving them out of the beam current.

\section{Spectrographic Analysis}

A qualitative spectrographic analysis was made of deposits on several coated glass slides and samples of deposits found in the vacuum tank. These analysis confirmed the elements of the backsputtered materials for each test segment. Slides used in facilities without insulating liners collected primarily copper (from the liquid nitrogen baffle), and chromium, nickel, and iron (from the stainless steel facility). When a target was used, the primary element detected was the target material. Analysis of a section of the insulating material taken from the facility after the test using the copper target revealed strong evidence of silicon and aluminum (the only traceable elements of silicon dioxide and aluminum oxide) but only traces of copper. The same analysis after the test using a platinum target revealed strong evidence of platinum as well as silicon and aluminum.

\section{Facility and Testing Requirements}

The effect of backsputtered material from the facility on glass coated grid performance places some restrictions on the type of environment in which these grids can be tested for extended periods of time. The possible test environments include

(1) Metal tank or target

(2) Tank lined with low vapor pressure nonconducting material

(3) Tank lined with high vapor pressure material (i.e., frozen mercury target)

(4) Space

There are several possible competing processes which may affect grid performance. These include

(1) Erosion of grid metal or glass by ion bombardment

(2) Change of electric fields in region of beam extraction by deposition of sputtered conducting material on grid surfaces

(3) Change of electric fields by deposition of sputtered non-conducting material on grid surfaces

Those effects which might be expected in each environment are shown in Table III. Erosion by ion bombardment will always occur in any environment. The erosion must be reduced to a rate which will produce insignificant detrimental changes over the required grid lifetime. Deposition of sputtered metal on glass surfaces must be avoided since this is known to significantly alter the beam current capability of the grid. However, sputtered insulator deposited on glass probably would not alter the electric field and hence would not be considered harmful. However there is the possibility that backsputtered metal might replenish some metal lost through ion erosion and thus reflect an erroneously low ion erosion rate.

The same arguement applies to the deposition of sputtered non-conducting material on glass surfaces. 
The effect of non-conducting materials on metal surfaces is not known, but it certainly is possible that these coatings may alter the electric field in the extraction region.

The use of a high vapor pressure target material would prevent the condensation of this material on the relatively warm $\left(150^{\circ} \mathrm{C}\right)$ surfaces of the thruster. In addition, the sputtered material from this type of target could easily be cryopumped to maintain sufficiently low background pressures. This environment most closely duplicates the grid test conditions to be expected in space.

It may also be possible to eliminate the deposition of sputtered materials rather than eliminating the materials themselves. A change in the design of the glass coated accelerator grid to provide a high beam current capability may also eliminate the line of sight from the target source of backsputtered materials to all critical grid surfaces. However, testing would be required with the explicit purpose of proving the absence of any interaction between facility and accelerator grid capability.

\section{High Beam Current Grid}

The series of tests described have shown that geometry of the accelerator potential surfaces has a pronounced affect upon the ion beam current extraction capability. Efforts were made to design and fabricate a glass coated accelerator grid which was capable of 1.5 ampere ion beam current operation without requiring facility backsputtered material. All the designs were based on a shortening of the distance between the upstream glass surface and the nearest accelerator potential surface. A comparison of three basic grid geometries is shown in Fig. 15. Grid a is the conventional facility dependent grid. Grid b was sputtered with platinum so that a non-oxidizing conductive coating extended part way into the hole wall thus reducing the distance from the upstream glass surface to the nearest accelerator potential surface. Grid c was fabricated out of photo-chemically etched molybdenum and coated with glass by a method which prevented the glass from covering the molybdenum in the hole walls, again shortening the glass surface to accelerator potential surface distance. Grid $c$ is different than grid $b$ in that the most upstream accelerator potential surface is well defined and measurable. Results of testing this grid indicate the increase of ion beam current extration due to the shortening of the upstream glass surface to nearest accelerator potential surface distance is much greater than that predicted by the simple inverse square relationship for the parallel electrode space charge limited current. The performance of these three grids in a $7.6 \mathrm{~m}$ diameter $\mathrm{fa}-$ cility is shown in Fig. 16. Tests 8 and 17 (grids b and $c$ of fig. 15) required less than 35 minutes to reach a 1.5 ampere beam, and are obviously independent of the facility. Test 12 (grid a, fíg. 15) was a grid free of conductive coatings and required backsputtered material from the facility to increase the beam current capability and provide a 1.5 A beam current.

The data of Fig. 16 show two grid geometries which can be fabricated and can extract a $1.5 \mathrm{~A}$ beam without the requirement for material from the vacuum tank.
This does not necessarily mean that the facility will not in some way affect the grid performance. Further testing is required to determine this point as well as that of grid lifetime.

\section{Conclusion}

Tests of glass coated accelerator grids in different environments have shown grid beam current capability to depend on conductive material, sputtered from the facility, being deposited on the glass surfaces of the grid. In all cases where a conductive coating existed at the start of a test, the beam current rise would be determined by thermal response of the thruster and feed system. In all cases where a conductive coating did not exist, the beam current rise was much longer, being determined by the rate at which facility conductive material was being built up on the glass surfaces of the grid. This rate was in turn determined by the facility size and geometry. It was found that a $7.6 \mathrm{~m}$ diameter vacuum tank required as much as 25 hours of $30 \mathrm{~cm}$ diameter thruster operation to build up a conductive coating thick enough to provide a $1.5 \mathrm{~A}$ beam. Thus, a vacuum tank, which is large compared to the size of the thruster, can be used to properly evaluate a grid geometry over a period of several hours. However, extended life testing would cause facility grid interaction if steps were not taken to eliminate backsputtered material from the facility.

The test results indicate the desirability for testing in a facility with a high vapor pressure target material to prevent condensable backsputtered material from deposition on the relatively warm grid surfaces. An alternate approach is the design of a grid which would eliminate a line of sight from target material sources to critical surfaces of the glass coated accelerator grids.

Two grids with metallic surfaces to simulate a conductive backsputtered coating were tested. One grid had a coating of platinum deposited on glass surfaces. The platinum coating was unaffected by exposure to atmosphere. The second grid used a metal substrate geometry which simulated the conductive coating. Both grids extracted a 1.5 A beam current without the need for backsputtered material from the vacuum tank.

\section{References}

1. Barber, T. A., Goldsmith, J. V., and Edberg, J. R., "Spacecraft Electric Propulsion - Now?," Astronautics and Aeronautics, Vol. 6, No. 6, June 1968, pp. $38-47$.

2. Reader, P. D. and Regetz, J. D., Jr., "A Delta Boosted, Electrically Raised High Power Synchronous Satellite," Paper 69-1104, Oct. 1969, AIAA, New York, N.Y.

3. Bechtel, R. T., "Performance and Control of a 30Cm-Diam, Low-Impulse, Kaufman Thruster," Journal of Spacecraft and Rockets, Vol. 7, No. 1, Jan. 1970 , pp. 21-25. 
4. King, H. J. and Poeschel, R. L., "Low Specific Impulse Ion Engine," NASA CR-72677, Feb. 1970, Hughes Research Labs., Malibu, Calif.

5. Bechtel, R. T., "Component Testing of a 30Centimeter Diameter Electron Bombardment Thruster," Paper 70-1100, Aug. 1970, AIAA, New York, N.Y.

6. Banks, B., "Composite Ion Accelerator Grids," presented at the Electrochemical Society Third International Conference on Electron and Ion Beam Science and Technology, Boston, Mass., May 6-9, 1968.

7. Banks, B. A. and Bechtel, R. T., "1000-Hour Endurance Test of a Glass-Coated Accelerator Grid on a 15-Centimeter-Diameter Kaufman Thruster, " TN D-5891, 1970, NASA, Cleveland, Ohio.
8. Rawlin, V. K. and Pawlik, E. V., "A Mercury Plasma-Bridge Neutralizer," Journal of Spacecraft and Rockets, Vol. 5, No. 7, July 1968, pp. 814-820.

9. Finke, R. C., Holmes, A. D., and Keller, T. A., "Space Environment Facility for Electric Propulsion Systems Research, "TN D-2774, 1965, NASA, Cleveland, Ohio.

10. Wehner, G. K. and Rosenberg, D., "Mercury Ion Beam Sputtering of Metals at Energies 4-15 keV, " Journal of Applied Physics, Vol. 32, No. 5, May 1961, pp. 887-890. 


\begin{tabular}{|c|c|c|c|c|c|c|c|c|c|c|c|c|c|c|c|}
\hline & \multirow{2}{*}{$\begin{array}{c}\text { Run } \\
\text { no. }\end{array}$} & \multicolumn{3}{|c|}{ Grid surface resistance } & \multirow{2}{*}{ 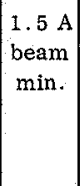 } & \multirow{2}{*}{$\begin{array}{c}1.5 \mathrm{~A} \\
\text { beam } \\
\text { amp-min. }\end{array}$} & \multirow{2}{*}{$\begin{array}{c}1.5 \mathrm{~A} \\
\text { beam } \\
\text { mono- } \\
\text { layers }\end{array}$} & \multirow{2}{*}{$\begin{array}{c}\text { Total } \\
\text { run } \\
\text { min. }\end{array}$} & \multirow{2}{*}{$\begin{array}{c}\text { Total } \\
\text { run } \\
\text { amp-min. }\end{array}$} & \multirow{2}{*}{$\begin{array}{c}\text { Total } \\
\text { run } \\
\text { mono- } \\
\text { layers }\end{array}$} & \multirow{2}{*}{$\begin{array}{c}\text { Percent } \\
\text { reduction } \\
\text { of glass } \\
\text { optical } \\
\text { trans- } \\
\text { mission }\end{array}$} & \multirow{2}{*}{$\begin{array}{c}\text { Rate of } \\
\text { reduction } \\
\text { of glass } \\
\text { optical } \\
\text { transmission, } \\
\% / \mathrm{hr}\end{array}$} & \multirow{2}{*}{$\begin{array}{c}\text { Facil- } \\
\text { ity } \\
\text { diam, } \\
\text { m }\end{array}$} & \multirow[t]{2}{*}{ Notes } & \multirow{2}{*}{$\begin{array}{c}\text { Grid } \\
\text { (fig. 1) }\end{array}$} \\
\hline & & $\begin{array}{c}\text { Before } \\
\text { run; } \\
\Omega\end{array}$ & $\begin{array}{l}\text { After run } \\
\text { vacuum, } \\
\Omega\end{array}$ & $\begin{array}{l}\text { After } \\
\text { run, } \\
\text { atm. } \Omega\end{array}$ & & & & & & & & & & & \\
\hline $\begin{array}{l}\text { Tests with an } \\
\text { initial coating }\end{array}$ & $\begin{array}{r}8 \\
9 \\
10 \\
7 \\
1 \\
5 \\
16 \\
14 \\
17\end{array}$ & $\begin{array}{l}<100 \Omega \\
<100 \Omega \\
<100 \Omega \\
<100 \Omega \\
\text { Cond(b) } \\
\text { Cond(c) } \\
\text { Cond (d) } \\
\text { Cond (d) } \\
\text { Short }\end{array}$ & $\begin{array}{l}<100 \Omega^{(a)} \\
<100 \Omega^{(a)} \\
<100 \Omega^{(a)} \\
<100 \Omega^{(a)} \\
1-10 \mathrm{MS}^{(a)} \\
\text { Cond } \\
\text { Cond } \\
\text { Cond } \\
\text { Cond } \\
\text { Short }\end{array}$ & $\begin{array}{c}<100 \Omega \\
<100 \Omega \\
<100 \Omega \\
<100 \Omega \\
1-10 \mathrm{M} \Omega \\
\infty \\
\infty \\
\infty \\
\text { Short }\end{array}$ & $\begin{array}{r}35 \\
22 \\
8 \\
6 \\
40 \\
50 \\
60 \\
75 \\
28\end{array}$ & $\begin{array}{l}31 \\
16.5 \\
5 \\
5.9 \\
29 \\
53 \\
66 \\
66 \\
23\end{array}$ & $\begin{array}{c}2 \\
1 \\
.5 \\
0 \\
48 \\
0 \\
5 \\
5 \\
2\end{array}$ & $\begin{array}{r}47 \\
113 \\
65 \\
400 \\
153 \\
400 \\
410 \\
4410 \\
34\end{array}$ & $\begin{array}{r}45 \\
151 \\
88 \\
610 \\
202 \\
424 \\
586 \\
250 \\
29\end{array}$ & $\begin{array}{r}4 \\
36 \\
6 \\
0 \\
310 \\
0 \\
41 \\
18 \\
2\end{array}$ & $\begin{array}{l}1 \\
5 \\
1 \\
-- \\
72 \\
8 \text { to } 16 \\
---- \\
-----\end{array}$ & $\begin{array}{r}0.021 \\
.044 \\
.015 \\
-0.47 \\
0.04 \text { to } 0.02 \\
\\
\end{array}$ & \begin{tabular}{|l|}
7.6 \\
7.6 \\
7.6 \\
$1.5(f)$ \\
1.5 \\
1.5 \\
7.6 \\
7.6 \\
7.6
\end{tabular} & $\begin{array}{l}1000 \mathrm{~V} \text { net accelerating potential } \\
1000 \mathrm{~V} \text { net accelerating potential } \\
700 \mathrm{~V} \text { net accelerator potential }\end{array}$ & $\begin{array}{c}1 \\
1 \\
1 \\
1 \\
1 \\
1 \\
2 \\
2 \\
\text { Fig. } \\
\text { 15-C }\end{array}$ \\
\hline $\begin{array}{l}\text { Tests without } \\
\text { an initial } \\
\text { coating, run } \\
\text { long enough } \\
\text { to reach high } \\
\text { beam current }\end{array}$ & $\begin{array}{r}6 \mathrm{~B} \\
4 \mathrm{~B} \\
\\
2 \\
13 \\
15 \\
1.5 \\
11\end{array}$ & $\begin{array}{c}\infty(e) \\
\infty(e) \\
\infty \\
\infty \\
\infty \\
\infty\end{array}$ & 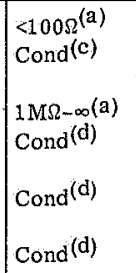 & $\begin{array}{c}<100 \Omega \\
\text { Not ex- } \\
\text { posed } \\
1 \mathrm{M} \Omega-\infty \\
\text { Not ex- } \\
\text { posed } \\
\text { Not ex- } \\
\text { po sed } \\
\infty\end{array}$ & $\begin{array}{r}55 \\
110 \\
110 \\
833 \\
940 \\
1500\end{array}$ & $\begin{array}{r}64 \\
139 \\
\\
90 \\
717 \\
717 \\
1187\end{array}$ & $\begin{array}{r}400 \\
440 \\
140 \\
52 \\
52 \\
\\
85\end{array}$ & $\begin{array}{r}70 \\
150 \\
177 \\
900 \\
1810 \\
2920\end{array}$ & $\begin{array}{r}87 \\
139 \\
188 \\
829 \\
2037 \\
3317\end{array}$ & $\begin{array}{r}550 \\
440 \\
\\
300 \\
60 \\
145 \\
\\
240\end{array}$ & $\begin{array}{c}99.96 \\
85 \text { to } 65 \\
60 \\
-- \\
-- \\
76\end{array}$ & $\begin{array}{l}1.4 \\
0.57 \text { to } 0.43 \\
0.34 \\
-\cdots \\
--- \\
0.026\end{array}$ & $\begin{array}{l}1.5^{(\mathrm{f})} \\
1.5^{(\mathrm{f})} \\
1.5 \\
7.6 \\
7.6 \\
7.6\end{array}$ & $\begin{array}{l}\begin{array}{l}\text { Platinum target } \\
\text { Copper target }\end{array} \\
1000 \mathrm{~V} \text { net accelerating potential } \\
1000 \mathrm{~V} \text { net accelerating potential } \\
1000 \mathrm{~V} \text { net accelerating potential }\end{array}$ & $\begin{array}{l}1 \\
1 \\
1 \\
2 \\
2 \\
2\end{array}$ \\
\hline $\begin{array}{l}\text { Tests without } \\
\text { initial coat- } \\
\text { ing, not run } \\
\text { long enough } \\
\text { to reach high } \\
\text { beam current }\end{array}$ & $\begin{array}{r}12 \\
3 \\
4 \mathrm{~A} \\
6 \mathrm{~A}\end{array}$ & $\begin{array}{l}\infty \\
\infty \\
\infty \\
\infty\end{array}$ & $\begin{array}{l}\infty(\mathrm{d}) \\
\infty(\mathrm{e}) \\
\infty(\mathrm{e}) \\
\infty(\mathrm{e})\end{array}$ & $\begin{array}{c}\infty \\
\infty \\
\text { Not ex- } \\
\text { po sed } \\
\text { Not ex- } \\
\text { posed }\end{array}$ & $\begin{array}{l}-\cdots- \\
-\cdots- \\
-\cdots \\
-\cdots-\end{array}$ & $\begin{array}{c}--- \\
--- \\
---\end{array}$ & $\begin{array}{l}-- \\
-- \\
-- \\
--\end{array}$ & $\begin{array}{l}705 \\
652 \\
240 \\
\\
200\end{array}$ & $\begin{array}{r}590 \\
332 \\
122 \\
\\
91\end{array}$ & $\begin{array}{l}42 \\
-- \\
-- \\
--\end{array}$ & $\begin{array}{r}9 \\
6 \\
12 \\
8\end{array}$ & $\begin{array}{l}0.013 \\
.009 \\
.05 \\
\\
.04\end{array}$ & $\begin{array}{l}7.6 \\
1.5^{(\mathrm{f})} \\
1.5^{(\mathrm{f})} \\
1.5^{(\mathrm{f})}\end{array}$ & & $\begin{array}{l}2 \\
1 \\
1 \\
1\end{array}$ \\
\hline $\begin{array}{l}\text { High beam, } \\
\text { no metallic } \\
\text { source, dete- } \\
\text { rioration test }\end{array}$ & $\begin{array}{l}4 \mathrm{C} \\
5\end{array}$ & $\begin{array}{l}\text { Cond }(\mathbf{c}) \\
\text { Cond }(\mathbf{c})\end{array}$ & $\begin{array}{l}\text { Cond (c) } \\
\text { Condd(c) }\end{array}$ & $\underset{\infty}{\operatorname{Cond}(c)}$ & --- & $\begin{array}{r}---- \\
53\end{array}$ & $\begin{array}{l}-- \\
--\end{array}$ & $\begin{array}{l}240 \\
400\end{array}$ & $\begin{array}{l}300 \\
424\end{array}$ & -- & $\begin{array}{l}12 \\
8 \text { to } 16\end{array}$ & $\begin{array}{l}0.05 \\
0.04 \text { to } 0.02\end{array}$ & $\begin{array}{l}1.5^{(\mathrm{f})} \\
1.5^{(\mathrm{f})}\end{array}$ & $\begin{array}{l}\text { No beam decrease } \\
\text { Beam decrease at } 33 \mathrm{~mA} / \mathrm{hr}\end{array}$ & $\begin{array}{l}1 \\
1\end{array}$ \\
\hline & $\begin{array}{l}\text { (a) } \mathrm{Ma} \\
\text { (b) } \\
\text { (c) } \\
\text { (d) } \\
\text { (d) } \\
\text { (e) } \\
\text { (f) } \\
\text { (f) } \\
\text { Fa }\end{array}$ & $\begin{array}{l}t \text { mea sur } \\
\text { sed on me } \\
\text { sed on lac } \\
\text { cility witl }\end{array}$ & $\begin{array}{l}\text { ed - inferre } \\
\text { eea surement } \\
\text { ck of conduc } \\
\text { h insulating }\end{array}$ & $\begin{array}{l}\text { re to atmo } \\
\text { ation, res } \\
\text { d from gr } \\
\text { s made on } \\
\text { ting mate } \\
\text { liners. }\end{array}$ & $\begin{array}{l}\text { osphere } \\
\text { sistance }\end{array}$ & $\begin{array}{l}\text { ormance } \\
\text { grid in si } \\
\text { facility } d\end{array}$ & decrease & & $\begin{array}{l}\text { e resistanc } \\
\text { history. } \\
\text { tory. } \\
\text { ne facility. } \\
\text { vious test }\end{array}$ & 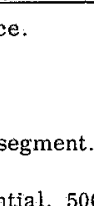 & & & & & \\
\hline
\end{tabular}

TABLE I: - SUMMARY OF TEST CONDITIONS AND RESULTS

[Note: $\infty$ indicates resistance greater than $17 \mathrm{~m} \Omega$ (instrument limit).] 


\begin{tabular}{|c|c|c|c|c|c|}
\hline Test & Facility & $\begin{array}{c}\text { Relative } \\
\text { amp-min } \\
\text { for given } \\
\text { thickness } \\
\text { (fig. 9) }\end{array}$ & $\begin{array}{c}\text { Relative time } \\
\text { to reach max } \\
\text { beam (fig. 9) } \\
\text { (Table I) }\end{array}$ & $\begin{array}{c}\text { Relative amp-min } \\
\text { to reach max } \\
\text { beam (fig. 9) } \\
\text { (Table I) }\end{array}$ & $\begin{array}{c}\text { Relative rate of } \\
\text { glass slide } \\
\text { transmission } \\
\text { reduction } \\
\text { (Table 1) }\end{array}$ \\
\hline $6 \mathrm{~B}$ & $\begin{array}{l}\text { Pt target only } \\
1.5 \text { m-diam facility }\end{array}$ & 0.25 & 0.50 & 0.71 & 0.24 \\
\hline $4 \mathrm{~B}$ & $\begin{array}{l}\text { Cu target only } \\
1.5 \text { m-diam facility }\end{array}$ & 0.51 & 1.0 & 0.97 & 0.6 to 0.8 \\
\hline 2 & $\begin{array}{l}1.5 \text { m-diam facility } \\
\text { No target or insu- } \\
\text { lating liners }\end{array}$ & 1 & 1 & 1 & 1 \\
\hline 11 & $\begin{array}{l}7.6 \text { m-diam facility } \\
\text { No target or insu- } \\
\text { lating liners }\end{array}$ & 22 & 13.7 & 13.2 & 13.1 \\
\hline
\end{tabular}

All values normalized to unity for test 2 .

TABLE II. - RANKING OF FACILITIES ACCORDING TO BEAM CURRENT RESPONSE, AND CALCULATED AND MEASURED COATING THICKNESS

\begin{tabular}{|l|c|c|c|c|}
\hline \multirow{2}{*}{} & \multicolumn{2}{|c|}{$\begin{array}{c}\text { Sputtered metal } \\
\text { deposition }\end{array}$} & \multicolumn{2}{c|}{$\begin{array}{c}\text { Sputtered insulator } \\
\text { deposition }\end{array}$} \\
\cline { 2 - 5 } & Glass & Metal & Glass & Metal \\
\hline Metal tank or target & Problem & $\begin{array}{l}\text { Possible } \\
\text { problem }\end{array}$ & No problem & No problem \\
\hline $\begin{array}{l}\text { Insulated tank } \\
\text { Low vapor pressure }\end{array}$ & No problem & $\begin{array}{c}\text { No } \\
\text { problem }\end{array}$ & $\begin{array}{l}\text { Possible } \\
\text { problem }\end{array}$ & $\begin{array}{c}\text { Possible } \\
\text { problem }\end{array}$ \\
\hline $\begin{array}{l}\text { Tank lined with high } \\
\text { vapor pressure tar- } \\
\text { get }\end{array}$ & No problem & $\begin{array}{c}\text { No } \\
\text { problem }\end{array}$ & No problem & No problem \\
\hline Space & No problem & $\begin{array}{r}\text { No } \\
\text { problem }\end{array}$ & No problem & No problem \\
\hline
\end{tabular}

TABLE III. - POSSIBLE TESTING PROBLEMS OF ION ENGINES IN DIFFERENT ENVIRONMENTS 


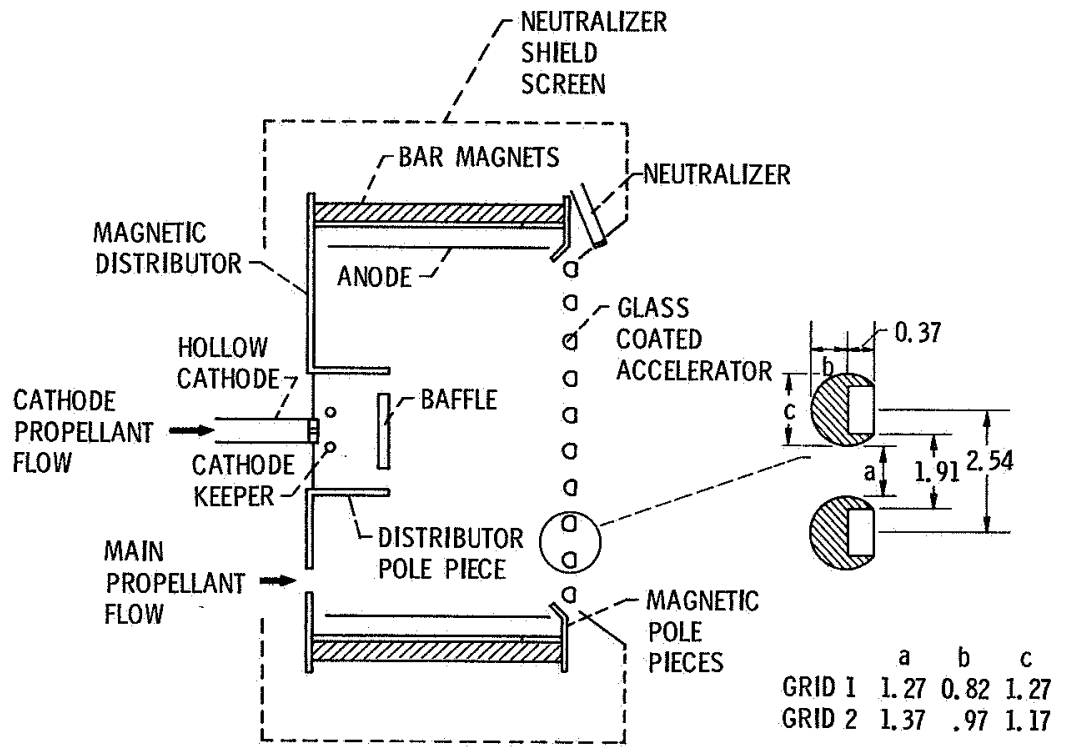

Figure 1. - Sketch of 30-centimeter diameter electron bombardment thruster showing glass coated accelerator grid (ciimensions in $\mathrm{mm}$ ). 


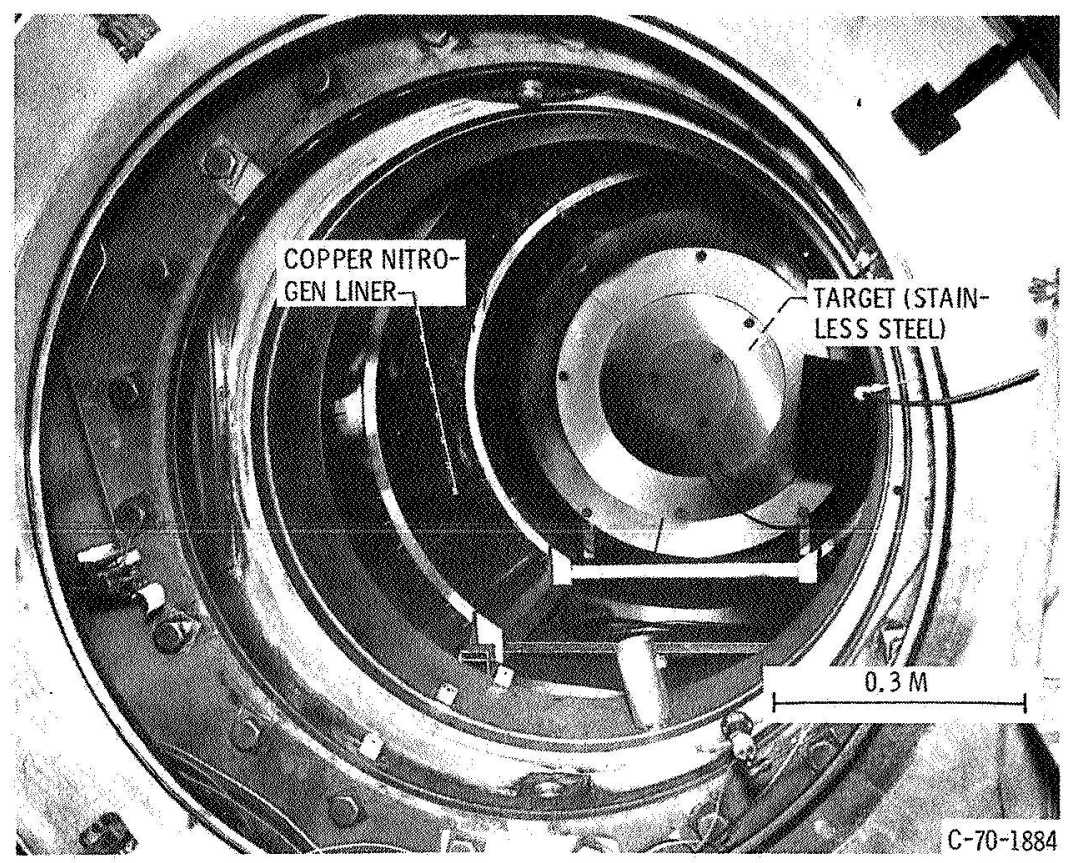

(a) Without insulating liners in place.

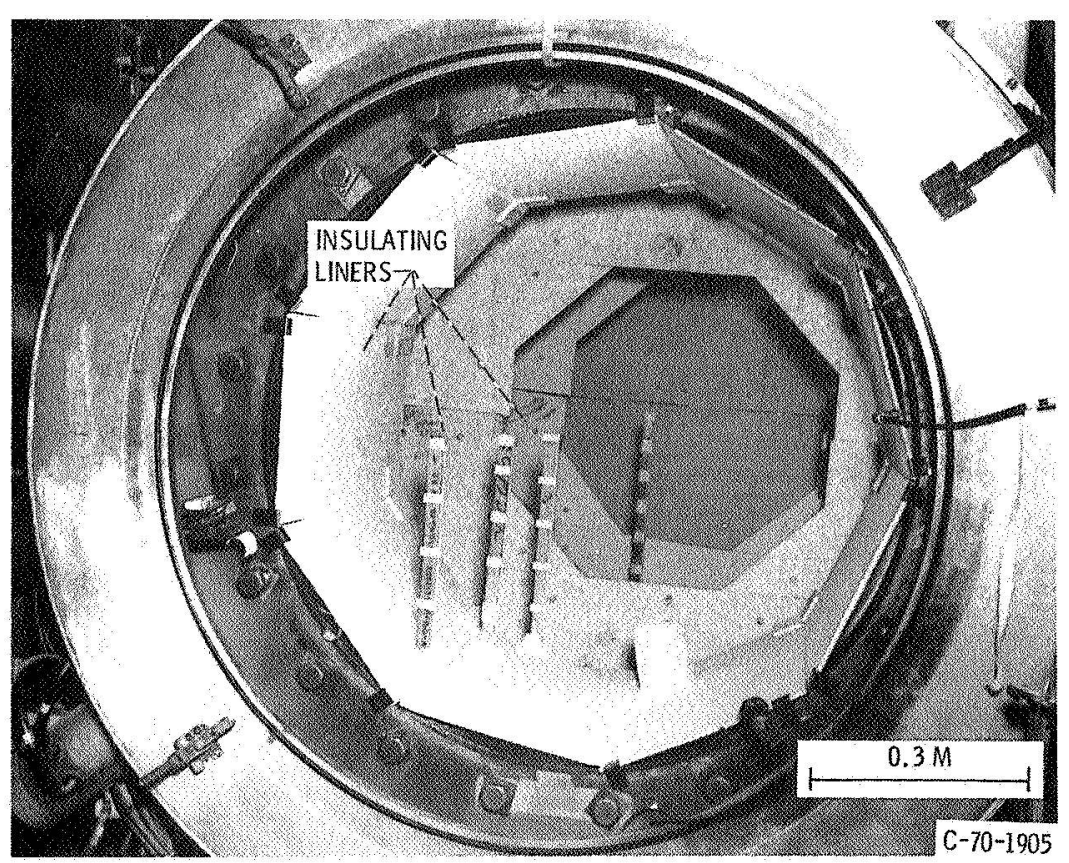

(b) With insulating liners in place.

Figure 2. -1.5 Meter-diameter by 4.6 meter long vacuum facility. 


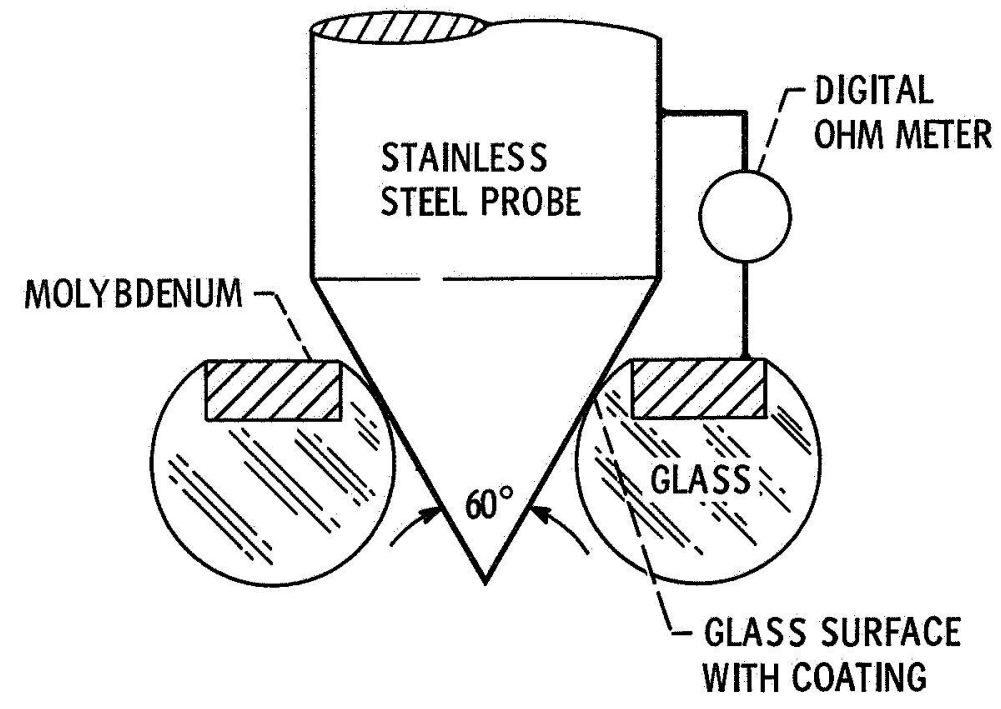

Figure 3. - Technique for measuring conductivity of coatings on downstream glass surfaces of accelerator grid.

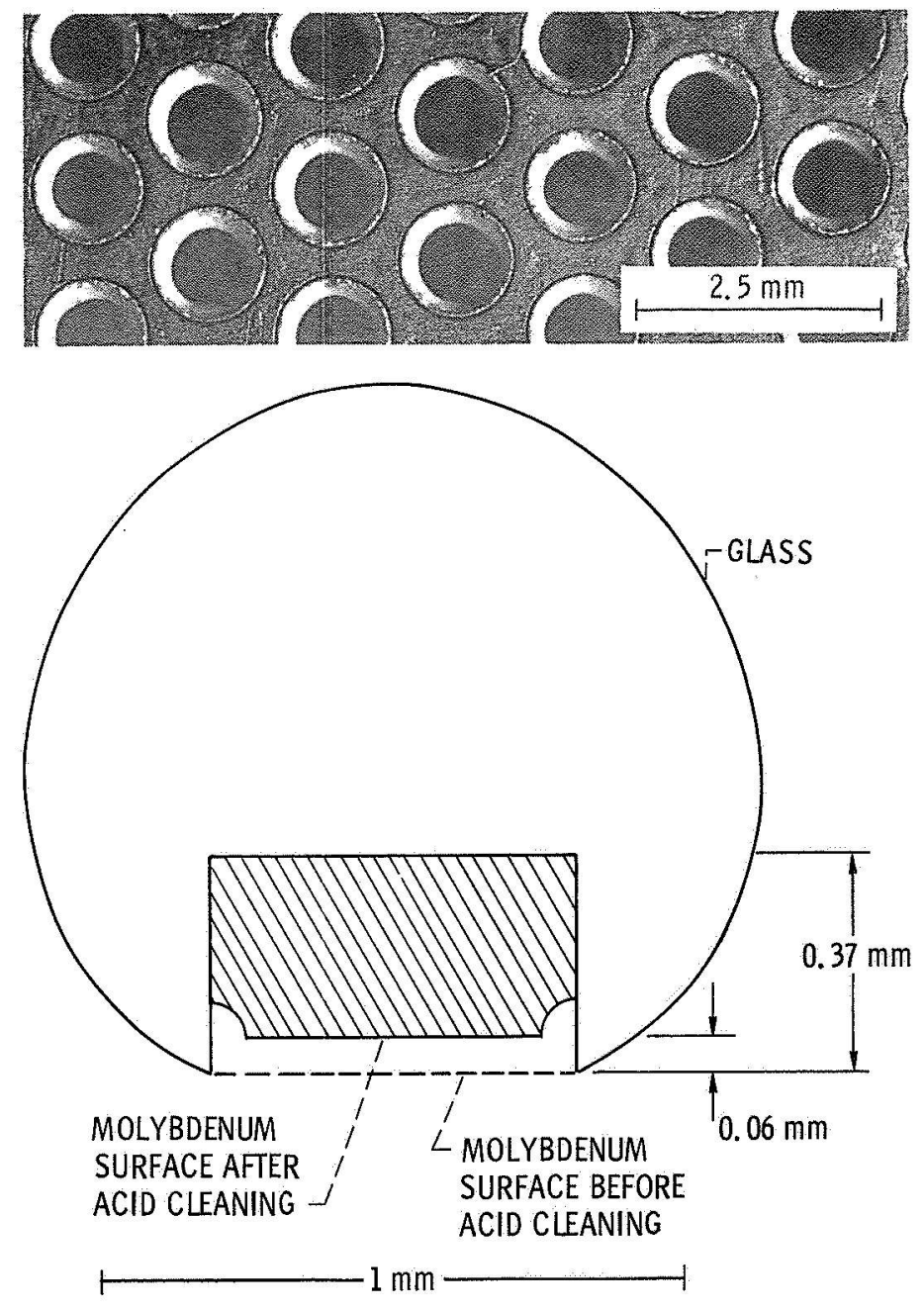

Figure 4. - Glass coated accelerator grid (downstream side) after being acid cleaned. 


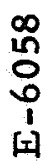

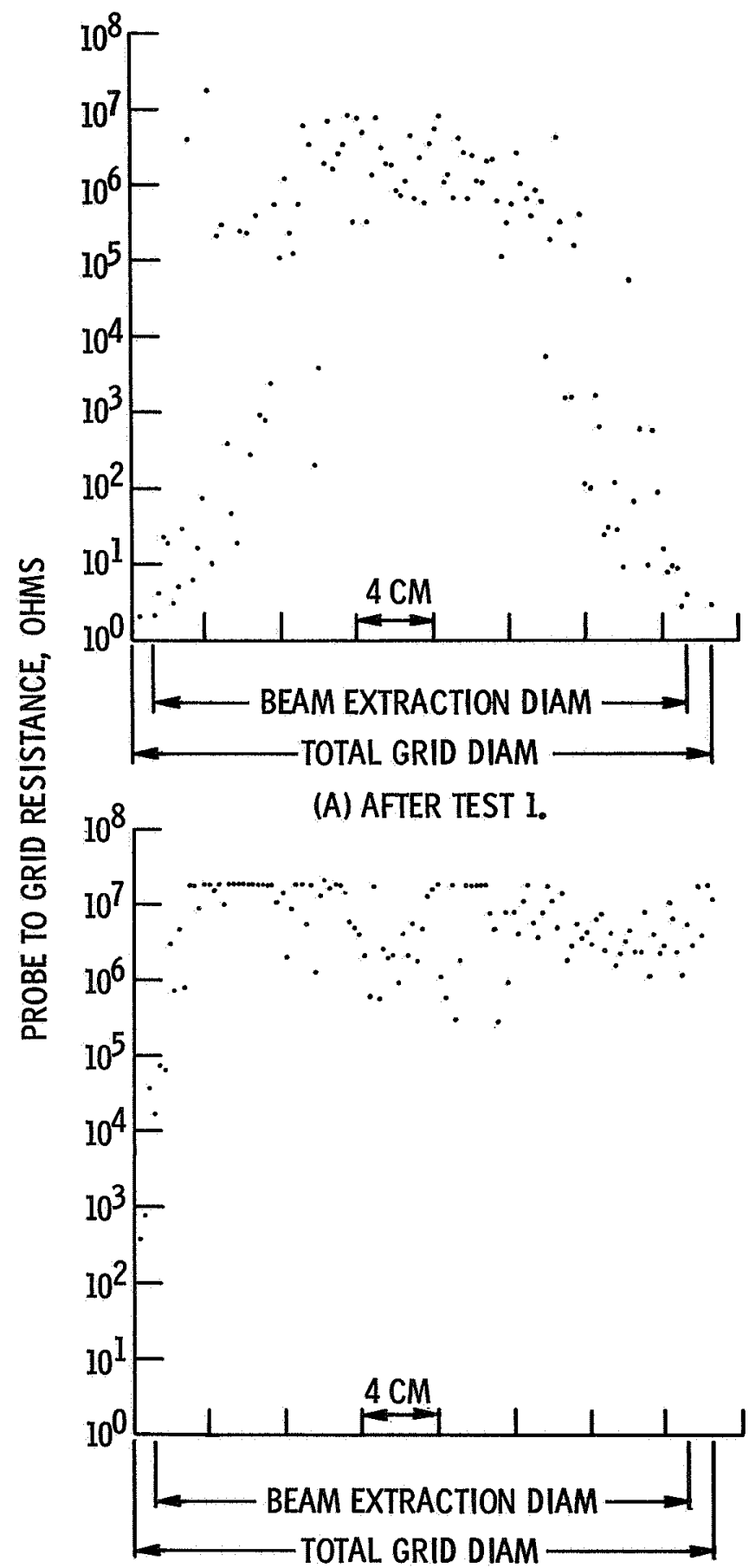

(B) AFTER TEST 2.

Figure 5. - Hole wall surface resistance measurements. 


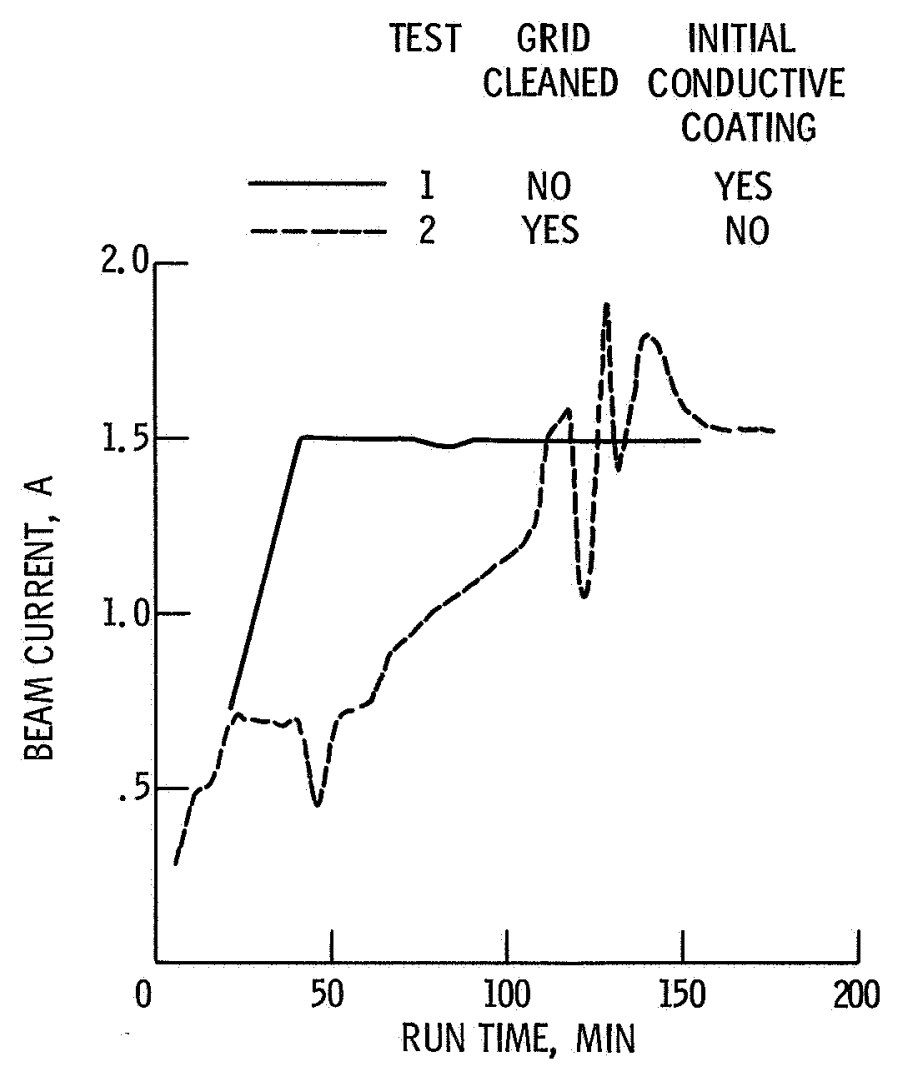

Figure 6. - Beam current-time history for tests 1 and 2.
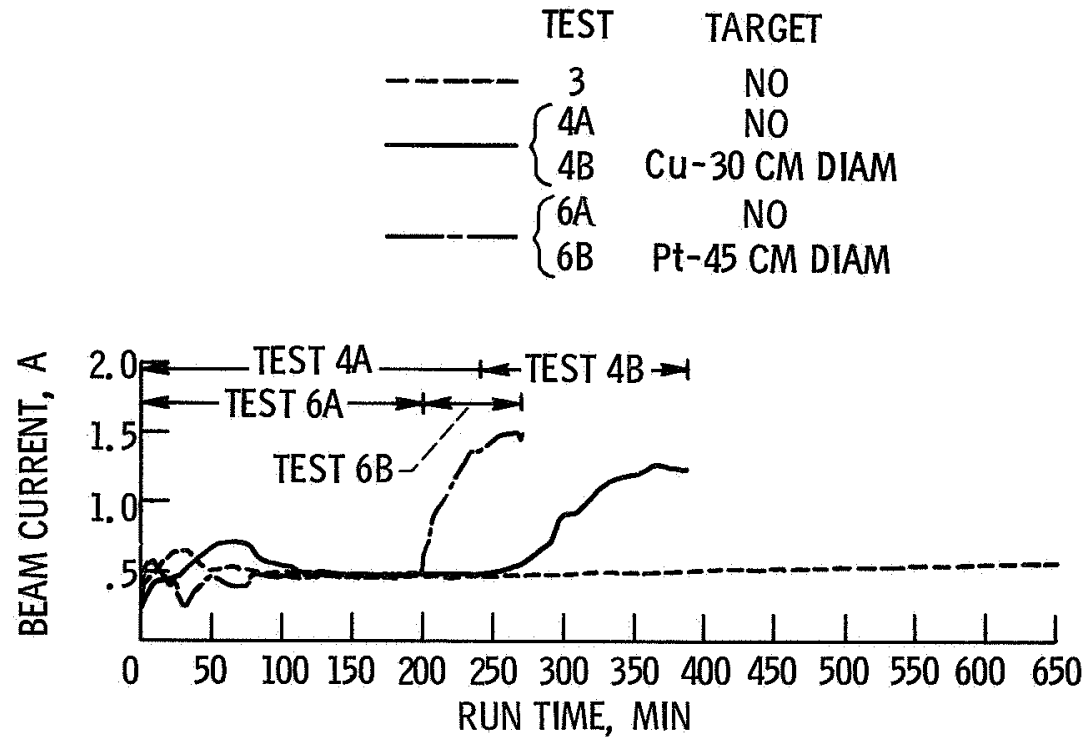

Figure 7. - Beam current-time history for tests in 1.5 meter diameter insulated facility without target and with copper and platinum targets. 


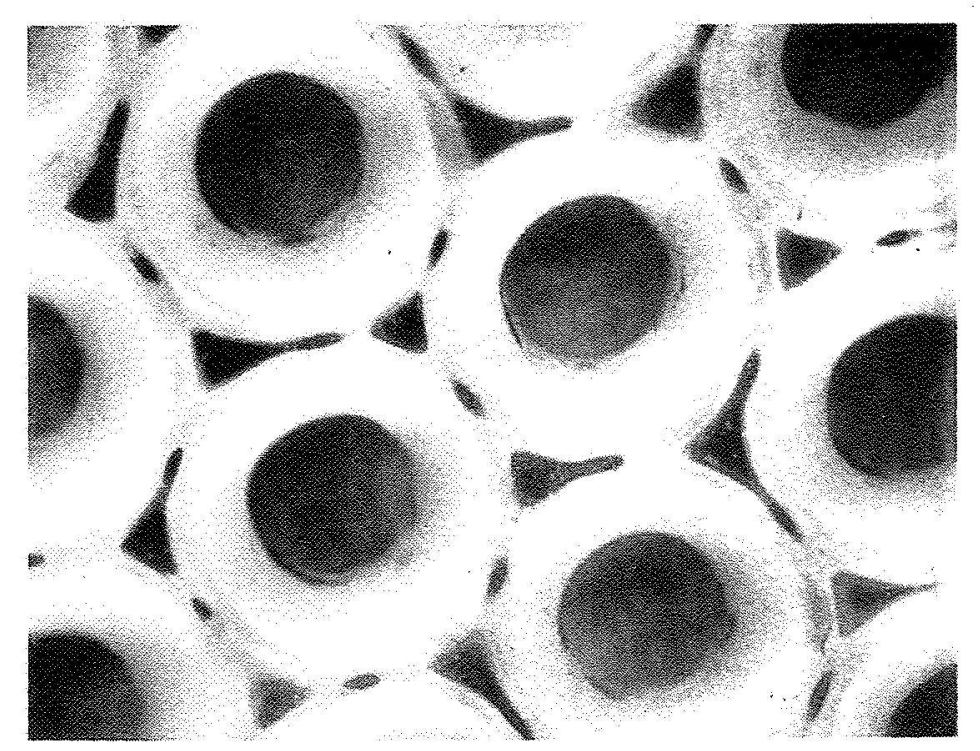

(a) Grid with typical conductive coating on glass.

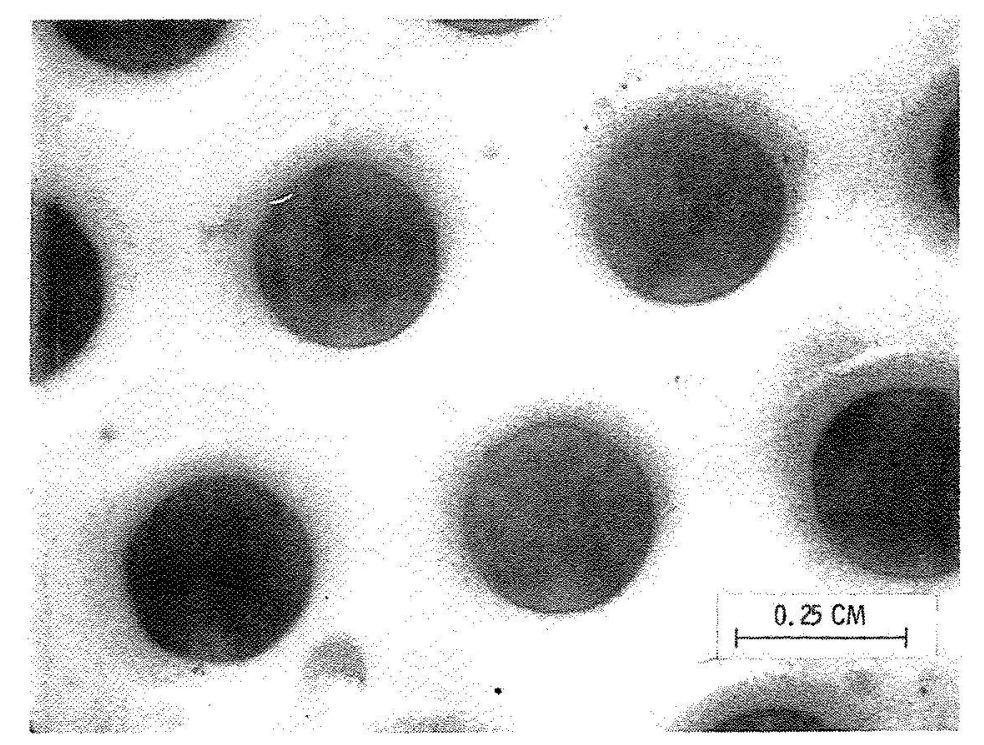

(b) Grid after test 68 with no conductive coating on glass.

Figure 8. - Photographs of upstream (glass) surface of grid.

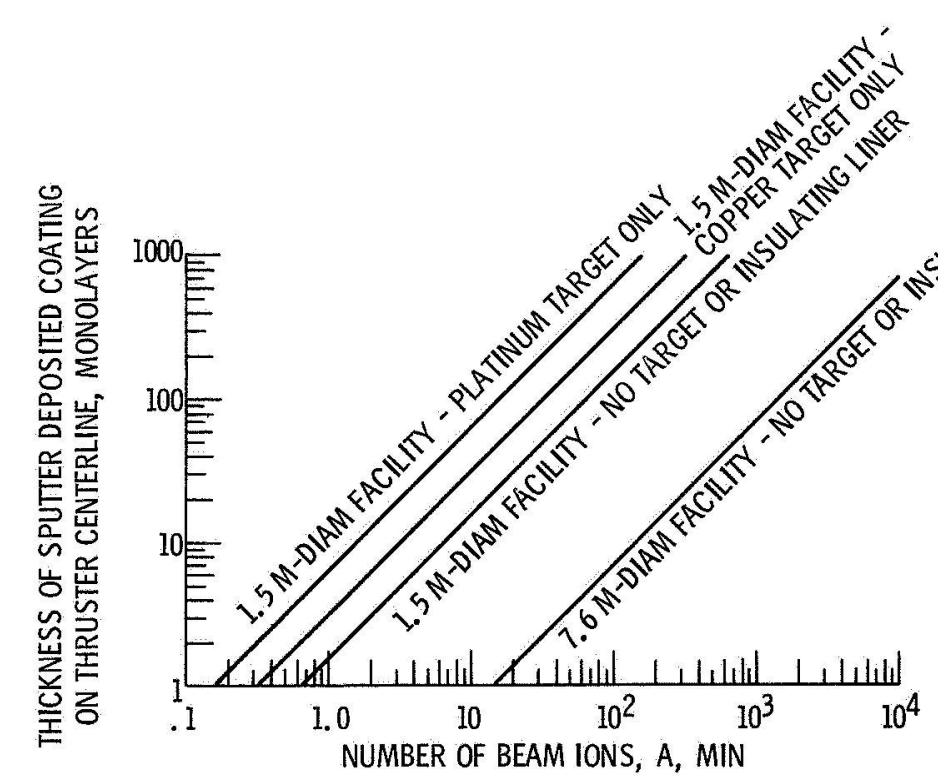

Figure 9. - Calculated thickness of sputtered material deposited on thruster centerline as a function of ampereminutes of run time for various targets and facilities. 


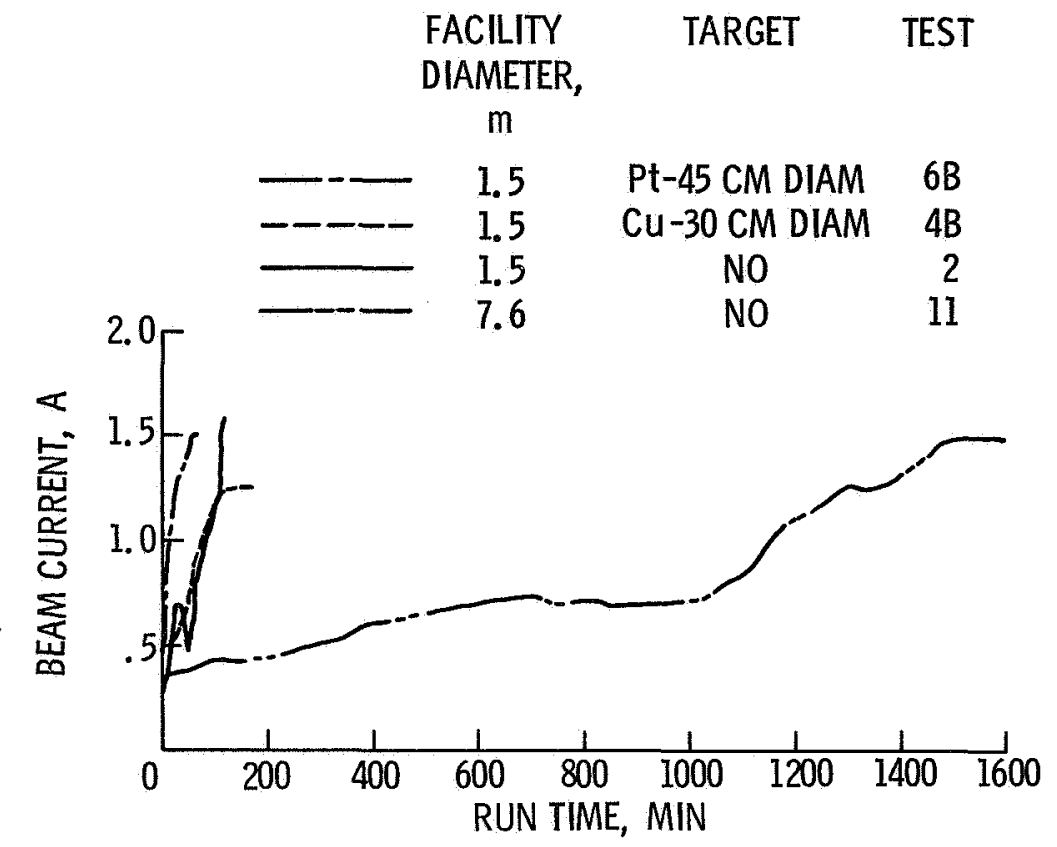

Figure 10. - Comparison of four different facility configurations for testing glass grids.

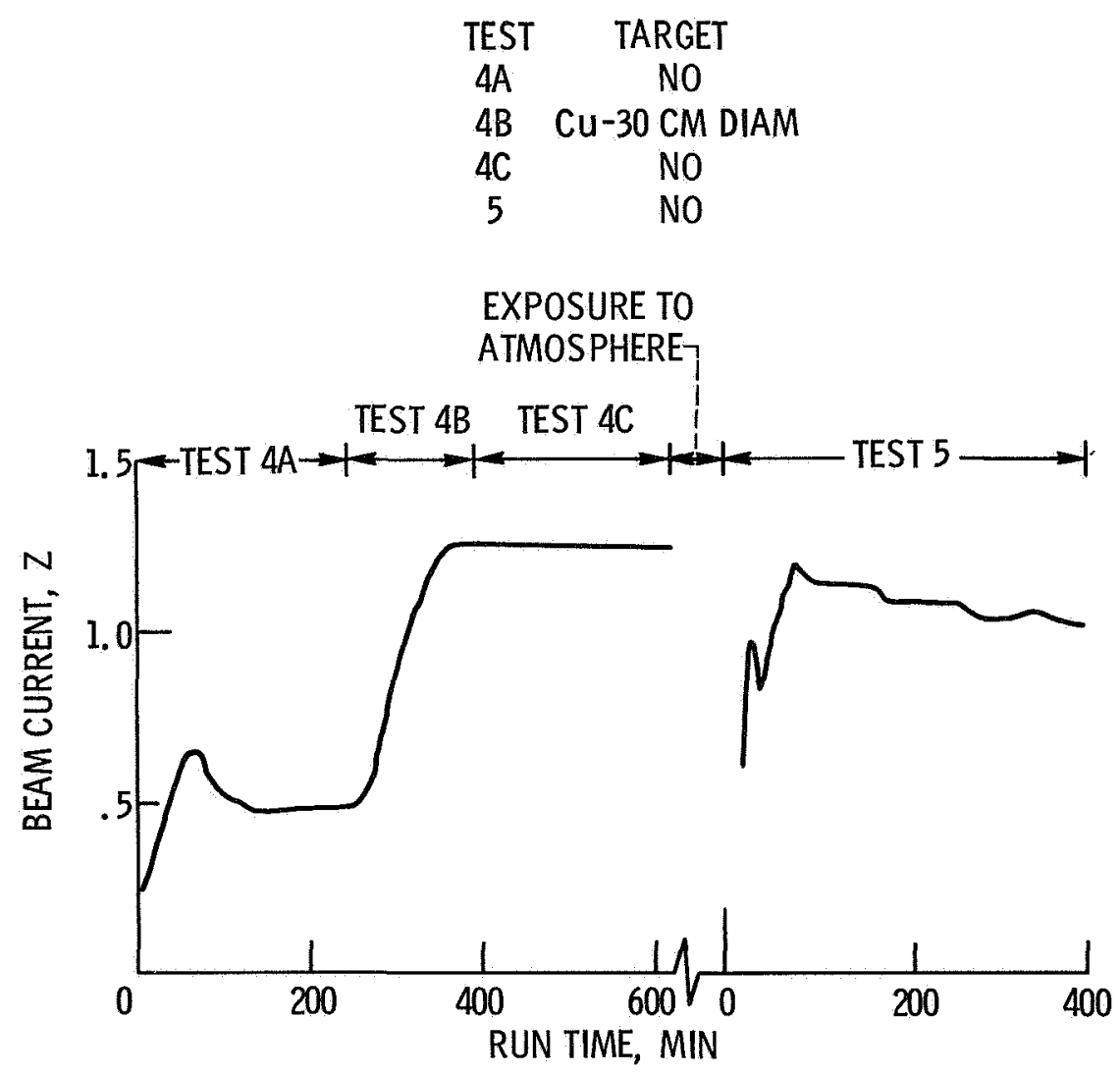

Figure 11. - Beam current-time history for tests $4 A$ through $C$ and test 5 in 1.5 meter-diameter facility with insulated liners showing effect of exposure to atmosphere. 


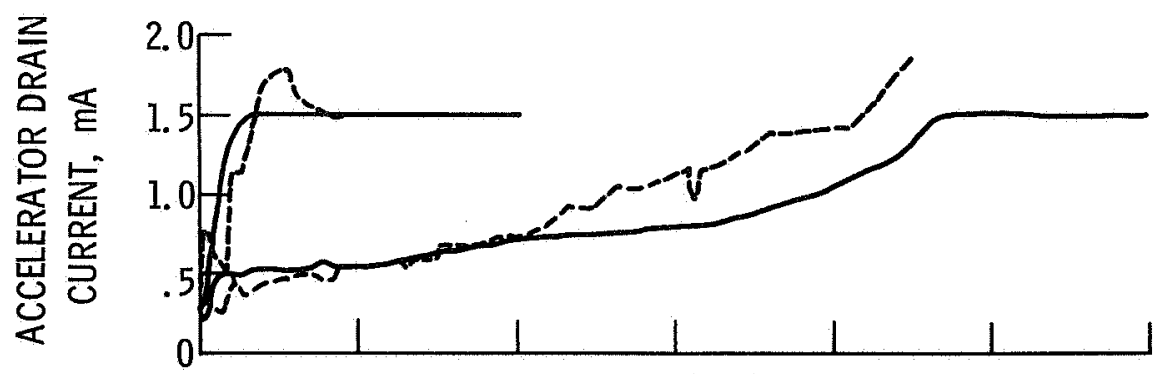

(A) BEAM CURRENT.

$\infty$
10
0
0
0
1
1

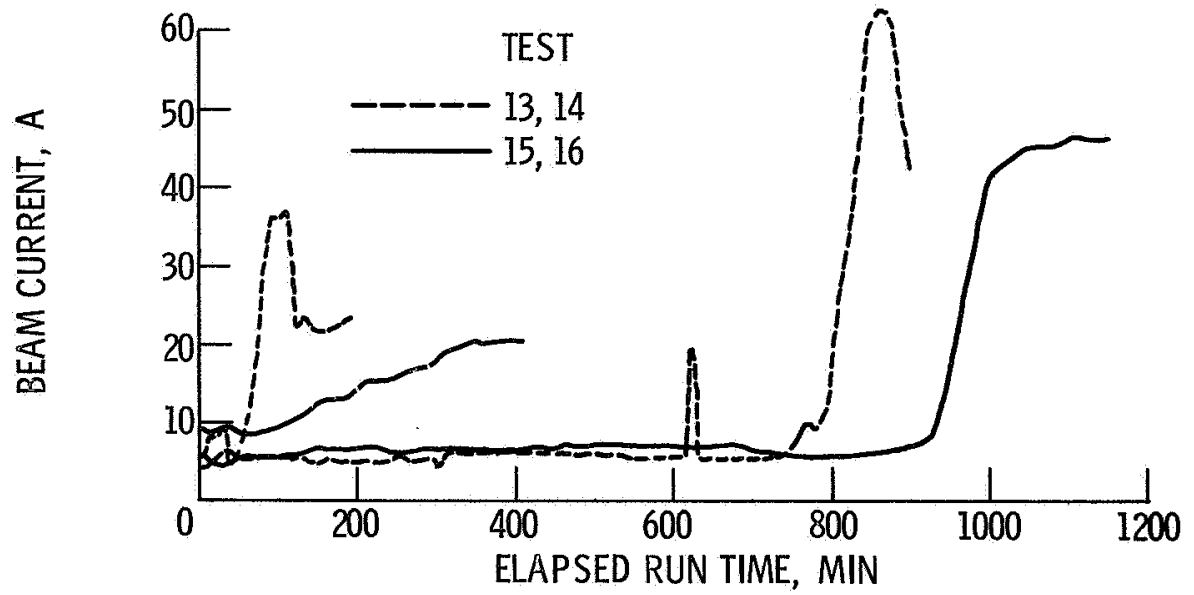

(B) ACCELERATOR DRAIN CURRENT.

Figure 12. - Startup performance of grid initially free of conductor coating, and restart of the same grid after having extracted $1.5 \mathrm{~A}$ beam and been kept at $10^{-7}$ torr vacuum.

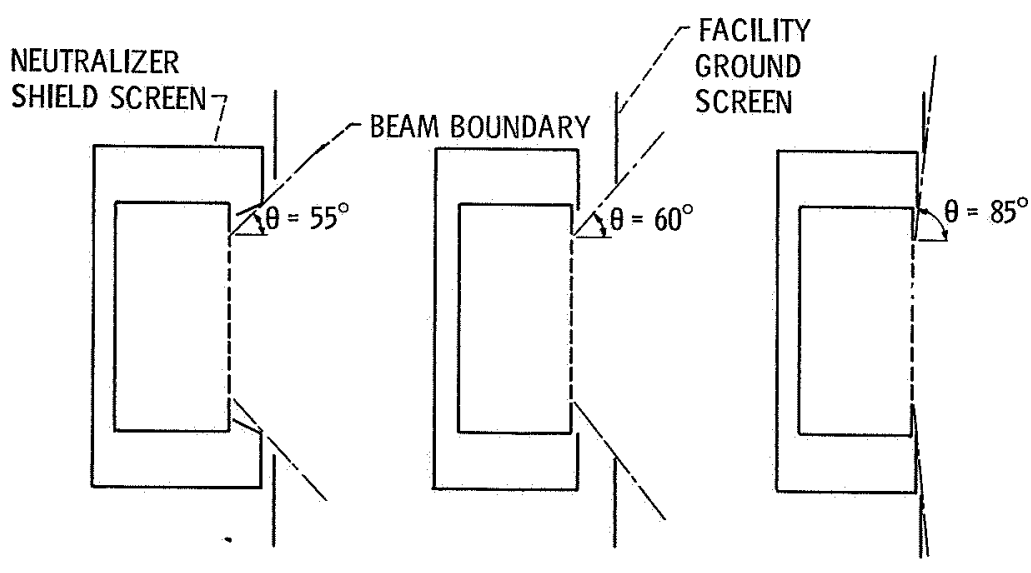

(A) TEST 13.

(B) TEST 15.

(C) TEST II.

$\theta \equiv$ MAXIMUM ANGLE OF DIVERGENCE OF PRIMARY BEAM ION CAN HAVE WITHOUT STRIKING NEUTRALIZER SHIELD OR FACILITY GROUND SCREEN

Figure 13. - Sketch showing different neutralizer shield screen and facility ground screen configurations tested. 

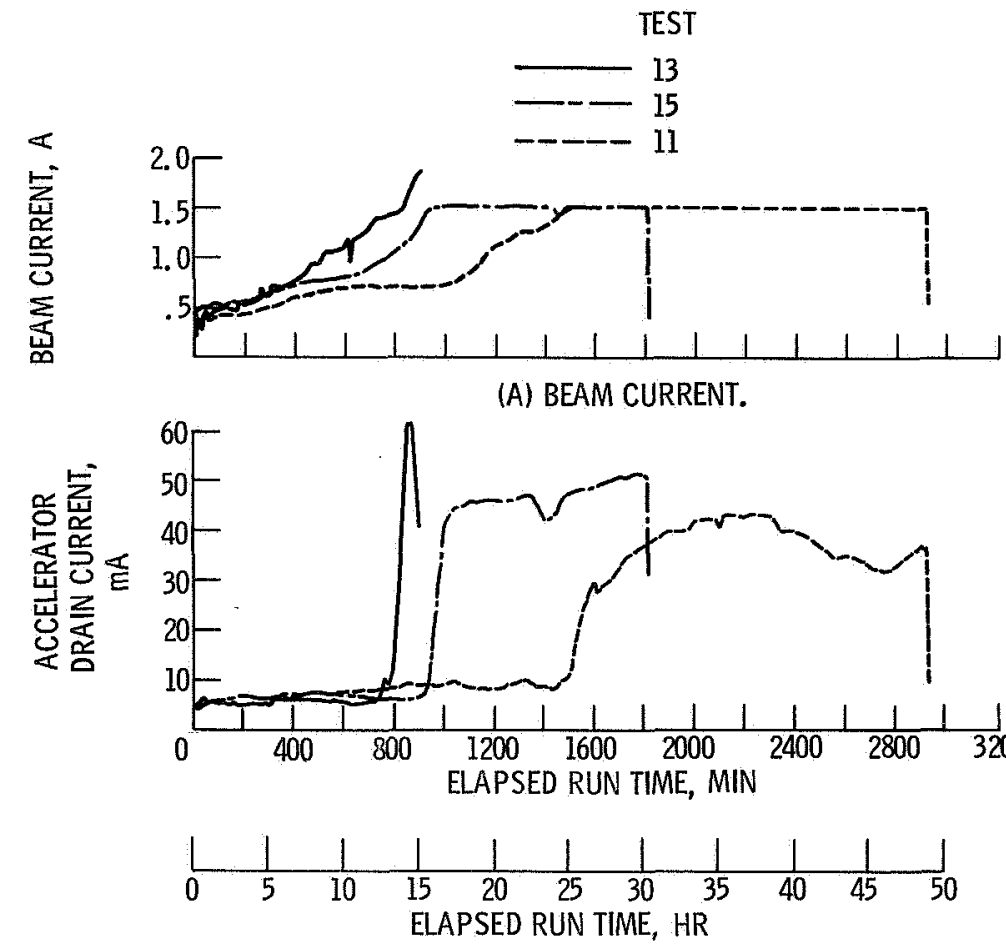

(B) ACCELERATOR DRAIN CURRENT.

Figure 14. - Effect of neutralizer shield screen and facility ground screen on start-up performer of grid having no critical conductive coating. 
$\infty$
0
0
1
I

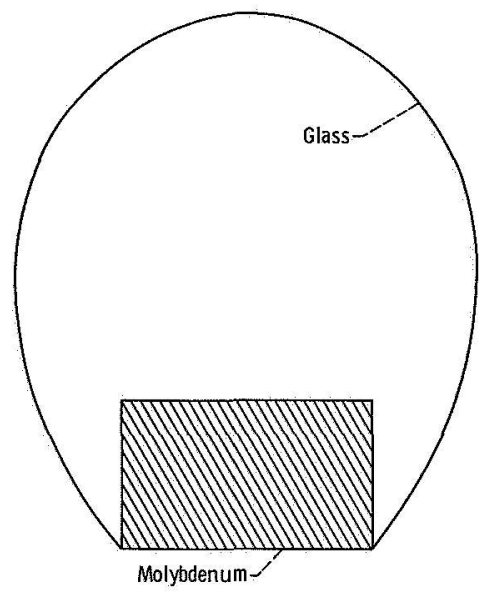

TEST GRID GEOMETRY

(FIG. 15)
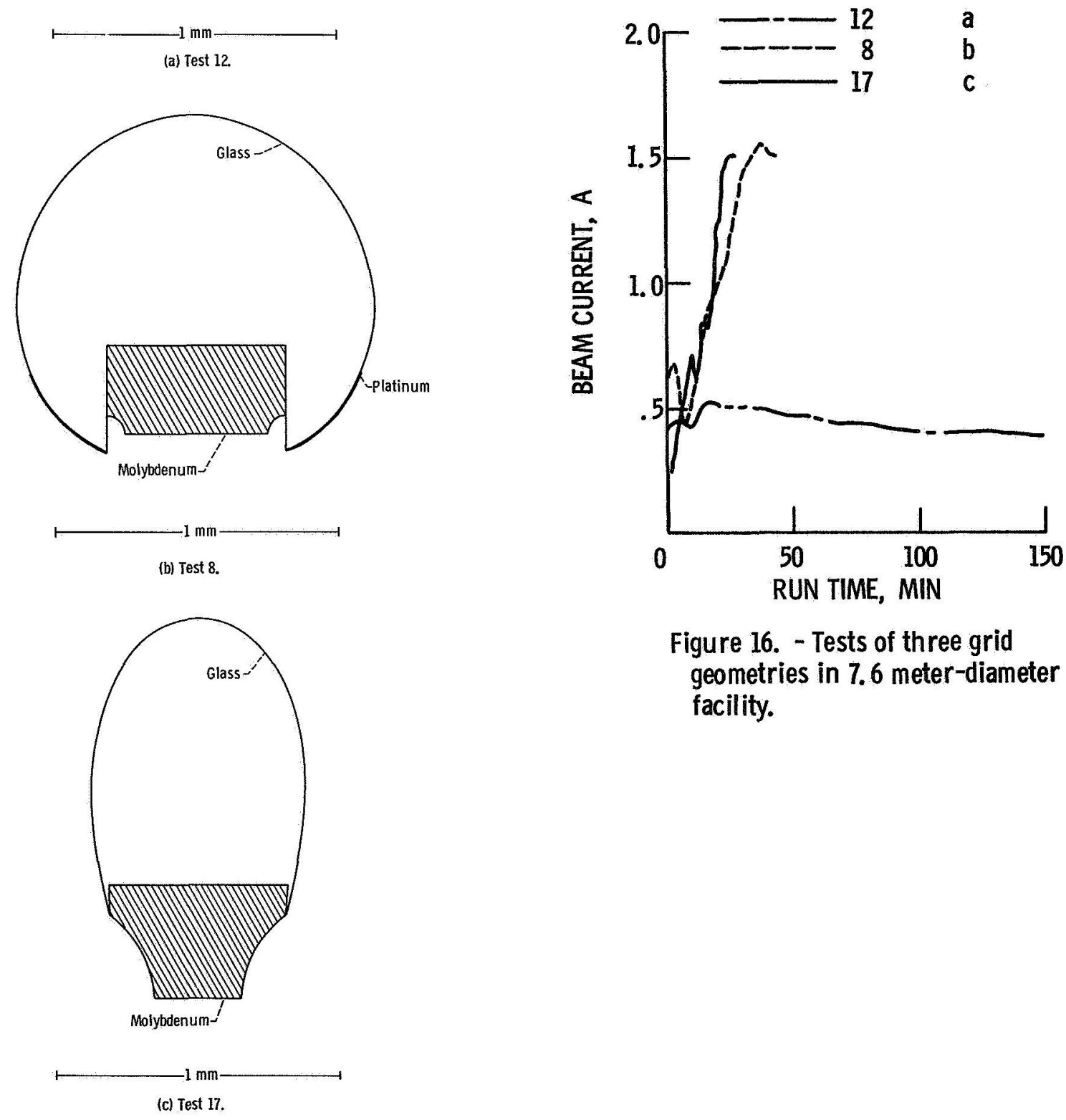

Figure 16. - Tests of three grid geometries in 7.6 meter-diameter facility.

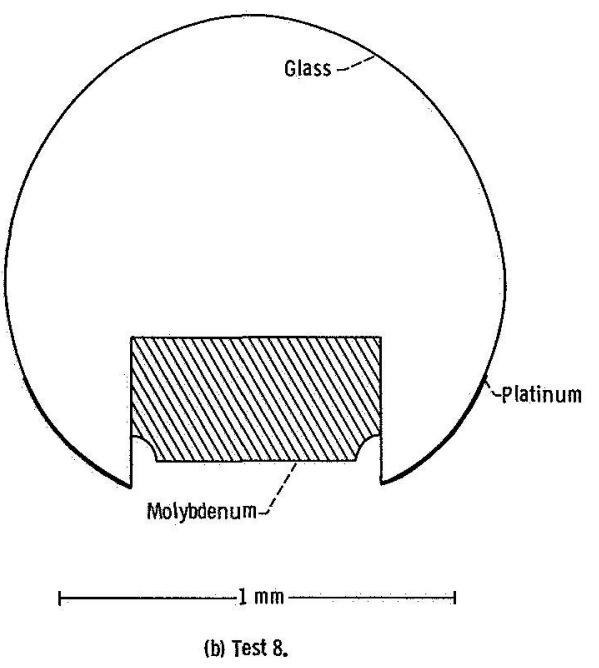

Figure 15. - Sketch of three grid geometries tested in $7.6 \mathrm{~m}$-diam 